\section{Paediatric dentistry}

\section{North/south divide}

Sir, in 2017, I was approached by the British Society of Paediatric Dentistry (BSPD) to see if I could use the most recent FP17 data from NHS Digital to construct a map showing the percentage of children ( 0 -2 years) within each Local Authority (LA) that attended an NHS practitioner in primary care in England. The NHS Digital data were based on local authorities (LAs) and these are sadly not coterminous with postal areas. This makes map construction based on postal areas quite complex, although less cluttered on an A4 sheet. The map shown in Figure 1 represents the distribution of this data according to the postal area. The BSPD request arose from the publication of a previous map showing the number of specialists in paediatric dentistry registered in each postal area. ${ }^{1}$ This first map highlighted a potential workforce issue with a noticeable shortage of specialists in some areas, while this map highlights attendance.

There appears to be a north/south divide on the attendance map and it is potentially useful as a datum to be compared with future maps following the recent launch of Starting Well, Smile4Life and the Dental Check by 1 (DCby1) initiatives.

A north/south divide was also coincidentally highlighted in a recent joint report by Appleby et al. in November 2017 produced by The Health Foundation and The Nuffield Trust. ${ }^{2}$ Their findings told of poorer oral health in the north. The north/south divide in both the map and the report are interesting and there will many hypotheses to explain them.

These attendance figures, in any case, appear to raise a significant safeguarding issue. Let us hope that our legislators take note.

R. W. Mills, Devizes

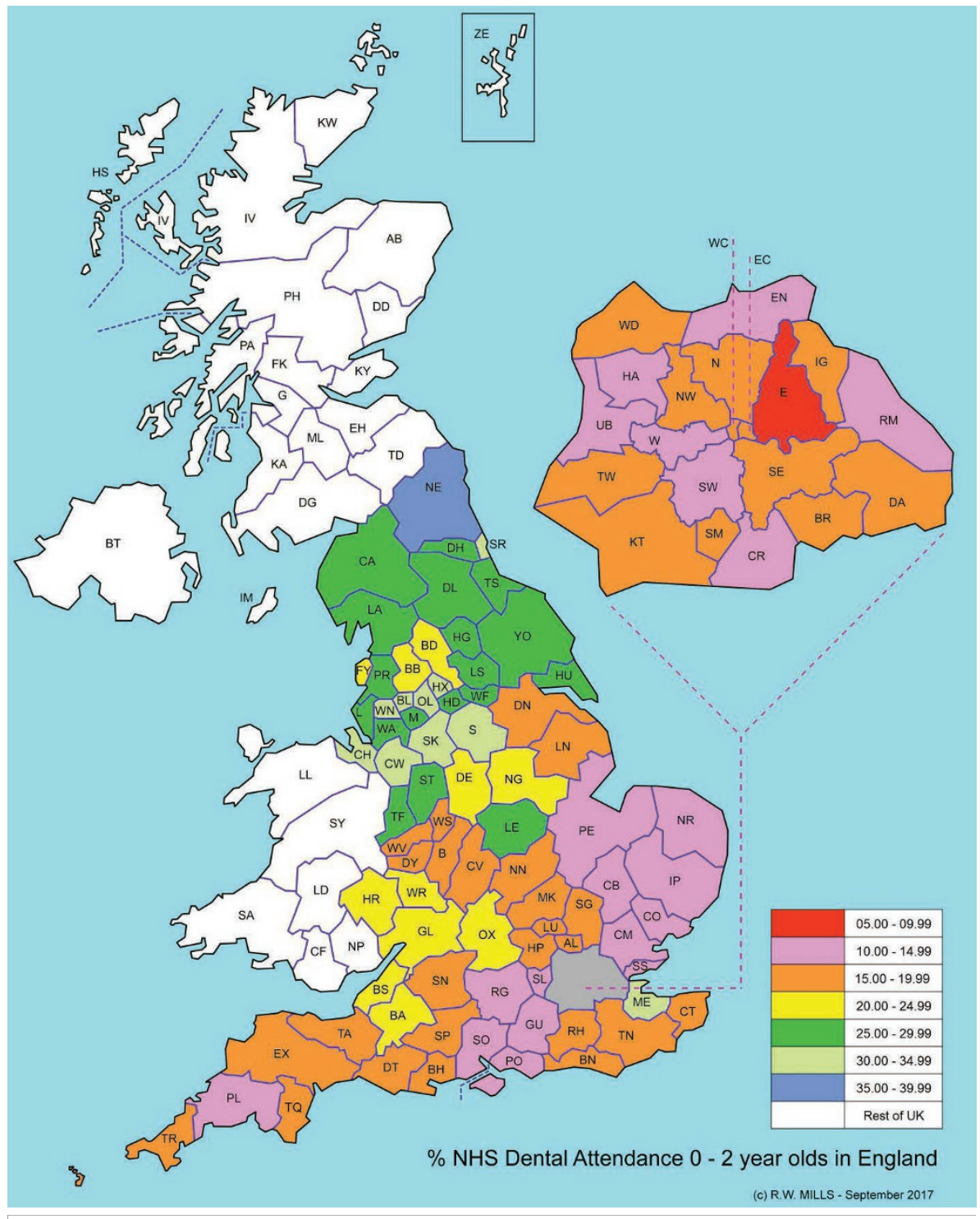

Fig. 1 Percentage primary care dental attendance of $0-2$-year-olds in England according to the postal area
1. Mills R W. Workforce planning: The specialist map. $\mathrm{Br}$ Dent J 2016; 220: 221.

2. QualityWatch. Root causes. Quality and inequality in dental health. Briefing. November 2017. Available at: http://www.qualitywatch.org.uk/sites/files/qualitywatch/field/field_document/QW\%20dentistry\%20 briefing_WEB.pdf (accessed February 2018).

DOI: $10.1038 /$ sj.bdj.2018.134

\section{Dental careers}

\section{Good preparation}

Sir, I am writing in response to the opinion piece entitled Defensive dentistry and the young dentist - this isn't what we signed up for (2017; 223: 757-758). As a foundation dentist, this piece is very relatable and I have found myself revisiting it over the last few weeks and would like to offer my thoughts.

In particular, I feel this piece rings true on one key point: many young dentists feel more anxious about litigation than any other aspect of starting their dental careers. I have found since leaving university that litigation is frequently at the forefront of my mind: when writing notes, explaining procedures, diagnosing periodontal conditions and deciding treatment plans. I feel that, compared to training at university, being a foundation dentist is daunting as your ability to make decisions is still developing but ultimately the litigious responsibility is as great in these first few months as it will be for the remainder of your career.

I agree with the author that foundation training is a steep learning curve. However, I do also believe it offers help and support to young dentists in regard to complaints and litigation. The recent addition of the mandatory portfolio has helped me consider my patient interactions, with the majority of my reflections being based on these interactions rather than my clinical work. In addition, many of the mandatory study days are related to note keeping and communication rather than being solely clinical in nature.

One aspect of the piece I would like to offer an alternative opinion on is that of foundation dentists entering dental core training to receive more protection from litigation in a more sheltered environment than in practice. As a foundation dentist intending to apply for core training, my main motive is that of gaining more experience and developing my skills, which in turn I hope will only improve my standard of care on returning to general practice. I believe that it is not the increased defence of a hospital setting that appeals to many 